\title{
PILOT HEART RATE DURING IN-FLIGHT SIMULATED INSTRUMENT APPROACHES IN A GENERAL AVIATION AIRCRAFT
}

A. Howard Hasbrook

Paul G. Rasmussen

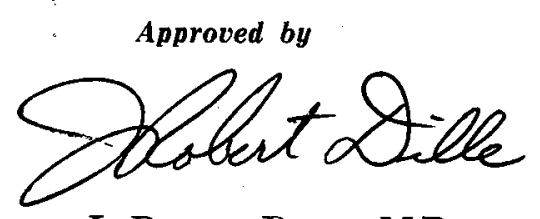

J. Robert Dirle, M.D.

Chief, Crvil Aeromedical

INsTiTute

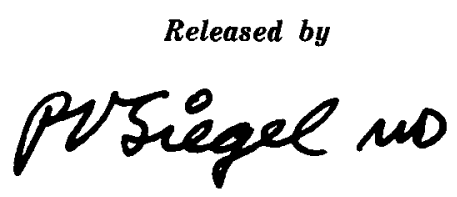

P. V. Siegel, M.D. Federal Arr Suraeon

April 1970

Department of Transportation

FEDERAL AVIATION ADMINISTRATION

Office of Aviation Medicine 


\section{ACKNOWLEDGMENT}

Space does not permit naming all the individuals and groups who contributed to the successful completion of this study; however, we would be remiss if we did not mention the "above and beyond" efforts of the FAA Oklahoma RAPCON/Tower personnel who so successfully and safely integrated hundreds of our simulated ILS approaches with other general aviation and air carrier traffic. To these and all the others who helped - our thanks.

Qualified requesters may obtain Aviation Medical Reports from Defense Documentation

Center. The general public may purchase from Clearinghouse for Federal Scientific and Technical Information, U.S. Dept. of Commerce, Springfield, Va. 22151 


\section{PILOT HEART RATE DURING IN-FLIGHT SIMULATED INSTRUMENT APPROACHES IN A GENERAL AVIATION AIRCRAFT}

\section{Introduction.}

Making an ILS approach through low clouds extending to within a few hundred feet of the ground is probably one of the most difficultbut routine-flying tasks facing the instrument rated pilot. The task of maneuvering a relatively high-speed vehicle within a constantly narrowing electronic "beam" requires rapid acquisition and evaluation of information provided by numerous instruments on the cockpit panel, frequent and often critical split-second decisions, and continuous application of control inputs. These task elements must be performed with reference to such variables as the aerodynamic response characteristics of the aircraft, information rates of the displays, and the display-control ratio which, in the case of the primary tracking display, is a constantly changing relationship.

The difficulties inherent in such a complex tracking task are frequently heightened by equipment and system designs that exhibit little consideration of the optimum response and operating characteristics of the human operator. ${ }^{2}$ Other factors which may contribute to the difficulty of the task, depending on individual circumstances, are the individual's subjective perceptions of the task, inadequate training and/or minimal proficiency, fatigue, chart reading, and radio communications.

Even this brief description of the total task implies the presence of a number of potential sources of stress inherent in making an ILS approach. If we follow the classification of mental stresses defined by Harris et al. ${ }^{4}$, we find that the separate stress-inducing characteristics of the total flying task assumed to be operating at any given time fall almost entirely into one or more of five categories of short-term stress. These are fear of failure, distraction, fear of harm, physical discomfort, and pacing or speed. Of these, physical discomfort stresses are probably the least significant in the present context. Although all the other categories would seem to be applicable in varying degree, pacing or speed stress seems particularly significant in that it can be directly identified with a quantifiable performance requirement of the flying task.

This report is based on heart rate data collected on subjects who acted as a control group for the study of pilot response to the use of aural glide slope cues during in-flight simulated ILS approaches in a light, general aviation aircraft. A number of significant limitations in the use of a single measure (such as heart rate) as a comprehensive stress indicator have been documented. ${ }^{6}$ However, changes in heart rate can be particularly indicative of short-term changes in stress ${ }^{810}$, and can be recorded without interfering with task performance.

\section{Equipment and Methodology.}

\section{Research Device}

A four-place single-engine general aviation type airplane (Figure 1) was used for the study.

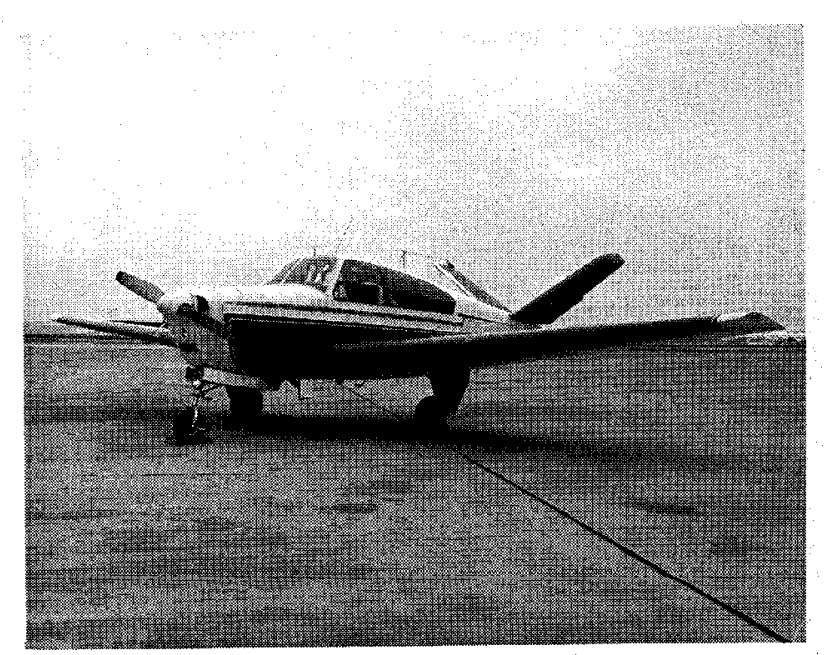

Figure 1. Aircraft used for in-flight study of pilot performance during simulated instrument approaches was typical of small, general aviation planes. 
The instrument panel display was representative of many such installations, consisting of a " $T$ " configuration (Figure 2), except for the location of the vertical speed indicator. It was moved to the right (Arrow \#1) from under the altimeter to provide a more centrally located space for the glide slope/localizer indicator (Arrow \#2).

Quick-removal "slats" (Arrow \#3) installed in the windshield area and to the left of the pilotsubject effectively simulated an instrument environment without interfering with the safety pilot's outside vision. The slats also eliminated the distracting weight and discomfort inherent in most hood devices normally worn on the head to simulate instrument flight.

A portable, battery-powered, seven-channel Lockheed (Model 417) tape recorder located behind the pilot's seat (Figure 3) recorded all inflight data. Its operation was monitored continuously by a research engineer seated on the right side of the plane behind the safety pilot. The recorded data was later transferred to a paper chart record in the laboratory by use of a Grass recorder.

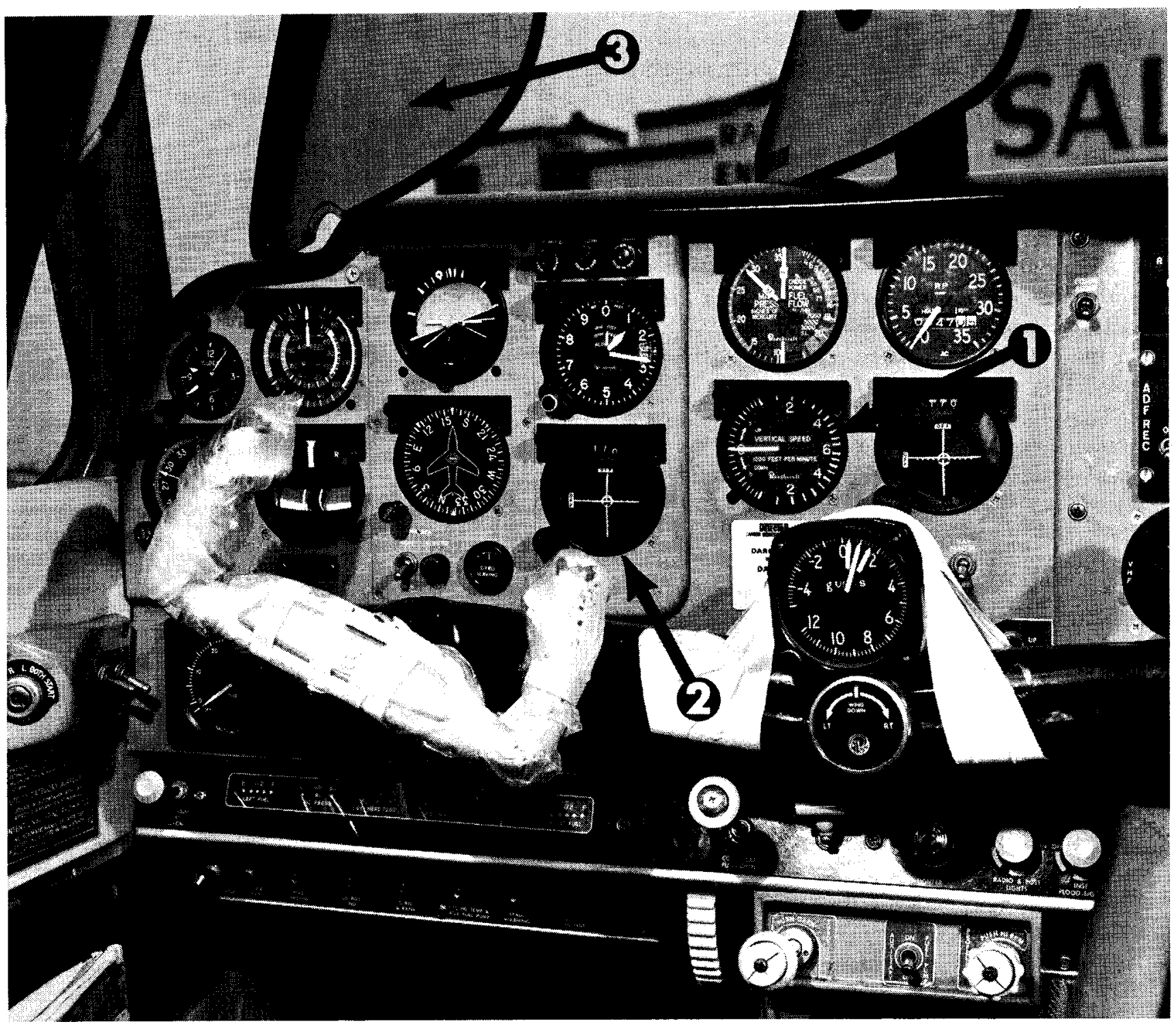

Figure 2. Instrument panel display in research aircraft. 


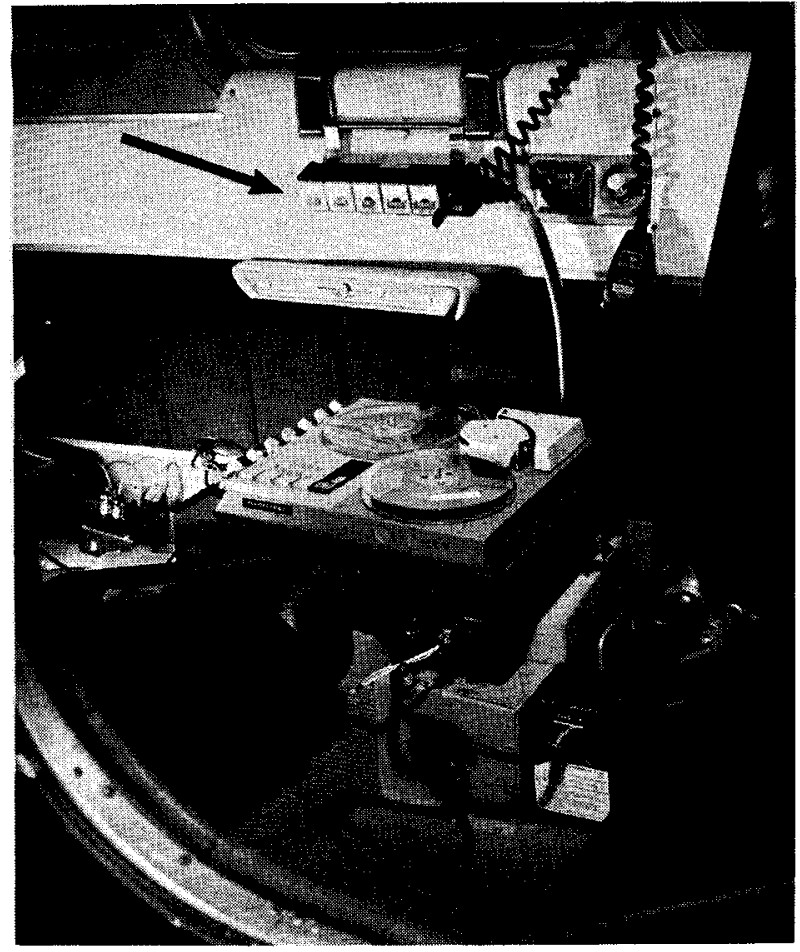

Frgure 3. Portable, seven-channel tape recorder used to obtain in-flight pilot performance data during simulated instrument approaches. Arrow indicates meter panel for monitoring inputs to recorder.

\section{Data Recorded}

Data recorded during the flights consisted of vertical deviation of the aircraft relative to the glide slope centerline; lateral deviation to either side of the localizer centerline; aircraft bank angle; vertical acceleration of the aircraft; heart rate of the pilot-subjects; and "event" information such as passage over geographical "fixes", calibration checks and observer's comments. However, only heart rate data were used for this report.

\section{Subjects}

Eight of forty pilots volunteering for the primary (aural glide slope) study were chosen as a control group. To obtain these eight (Table 1), the original forty pilots (all of whom possessed current FAA Airman Medical Certificates and FAA Instrument Ratings) were ranked from "high" to "low" on the basis of their number of hours of instrument flight experience. Some arbitrary weight was given to recency of experience and total flying hours for those subjects reporting approximately the same level of instrument ex-
TABLE I.-Age, experience, and ratings of subjects participating as control group for master study and for which heart rate data is presented in this report.

Ages are given to nearest birthday.

Total instrument hours include simulator training.

\begin{tabular}{|c|c|c|c|c|c|c|}
\hline $\begin{array}{c}\text { Sub- } \\
\text { ject } \\
\text { num- } \\
\text { ber }\end{array}$ & $\begin{array}{c}\text { Age } \\
\text { (Yrs.) }\end{array}$ & $\begin{array}{l}\text { Total } \\
\text { flight } \\
\text { hours }\end{array}$ & $\begin{array}{c}\text { Total } \\
\text { instru- } \\
\text { ment } \\
\text { hours }\end{array}$ & $\begin{array}{l}\text { Com- } \\
\text { mer- } \\
\text { cial } \\
\text { rating }\end{array}$ & $\begin{array}{l}\text { ATR } \\
\text { rating }\end{array}$ & $\begin{array}{l}\text { Flight } \\
\text { instru- } \\
\text { tor } \\
\text { rating }\end{array}$ \\
\hline $1 \ldots$ & 48 & 8,800 & 620 & & $\mathrm{X}$ & $X$ \\
\hline $2 \ldots \ldots$ & 37 & 600 & 60 & $X$ & & \\
\hline $3 \ldots$ & 41 & 11,200 & 650 & $\mathrm{X}$ & & $\mathrm{X}$ \\
\hline $4 \ldots$ & 48 & 1,685 & 79 & $X$ & & $X$ \\
\hline $5 \ldots$ & 48 & 12,271 & 3,057 & & $X$ & \\
\hline $6 \ldots$ & 37 & 1,000 & 140 & $\mathrm{X}$ & & $\mathrm{X}$ \\
\hline $7 \ldots$ & 42 & 1,500 & 105 & $\mathrm{X}$ & & \\
\hline $8 \ldots$ & 50 & 6,000 & 500 & $X$ & & $\mathrm{X}$ \\
\hline Mean & 44 & 5,382 & 651 & & & \\
\hline
\end{tabular}

perience. 'The list was then divided into eight levels of experience composed of five subjects each. The subjects in each level were then randomly assigned to the five groups constituting the main study. This method was chosen to assure relatively matched groups with regard to experience and initial ability while retaining the statistical requirement of random sampling of the subject population. Flying experience of the eight chosen for the control group ranged from 600 to 12,271 hours, with a mean of 5,382 hours; ages ranged from 37 to 50 years, with a mean of 44 years. Six had commercial pilot ratings and the remaining two had airline transport ratings. Five possessed flight instructor ratings. None had flown more than 10 hours instrument (simulated or actual) in the last 90 days; three had not flown at all during that period of time.

\section{ILS Facilities}

Two instrument landing approach (ILS) facilities were used for the study; one, serving runway 35L at Will Rogers World Airport, Oklahoma City, Oklahoma, was utilized when the wind was from the north; the other, a training facility serving runway 17 at the Chickasha, Oklahoma airport, was used when the wind was from the south. Approximate angle of both glide slope centerlines was $2-1 / 2^{\circ}$. 


\section{Experimental Procedure}

Prior to flight, three disposable electrodes were taped to the subject's chest at the sternum and checked in the laboratory to confirm proper functioning. The subject was then briefed on the manner in which the flight would be conducted. The subject was given a headset to wear during flight so as to exclude all radio communication and to minimize extraneous cockpit noise, while permitting the safety pilot to communicate with the subject via the interphone.

The aircraft was started, taxied to the active runway and "run-up" by the safety pilot. The "slats" were then installed in front of the subject, effectively blocking his view of the outside world. The take-off and initial climb-out were made by the safety pilot. About 1-1/2 minutes after take-off, with trim set for "cruise-climb", control of the aircraft was given to the subject with instructions to climb to, and maintain, a specified altitude. At the specified altitude, the subject was told to execute a series of left and right turns using bank angles of $10^{\circ}, 20^{\circ}$, and $30^{\circ}$, respectively. Following these maneuvers, the landing gear was extended and the flaps, power, and RPM were set in the landing approach configuration by the safety pilot. The subject then practiced a partial-power descent to approach altitude, varying power as required to maintain a specified rate of descent.

Regardless of the subjects' degree of familiarity with the aircraft, total in-flight indoctrination time for each subject was approximately $20 \mathrm{~min}$ utes, and involved identical maneuvers. Limiting this familiarization period to an "under-the-hood" environment was considered to be effective in minimizing performance variability due to the subjects' varying degrees of experience with the size, type, and specific aircraft used for the study.

Ten straight-in ILS landing approaches were then performed at approximate 10-minute intervals (Figure 4). Prior to each approach, the safety pilot placed the aircraft on the centerline of the glide slope/localizer "beam" at a fixed geographical point. Speed, power, gear, and flaps were set in "approach configuration" before turning control of the aircraft over to the subject. In this way, all subjects started their approaches in identical approach geometry from the same point in space, without the responsibility for navigating to that point. Upon completion of each approach at the middle marker, the safety pilot raised the landing gear and flaps, instructing the subject to "go around." All air traffic control conversations were excluded from the subject's headset during the approaches. Also, in order to further eliminate any uncontrolled variables which might adversely affect the intent of the main study, the subjects' primary attention was devoted to flying the aircraft; their attention was not diverted to other tasks such as chart reading or checking engine gauges, etc.

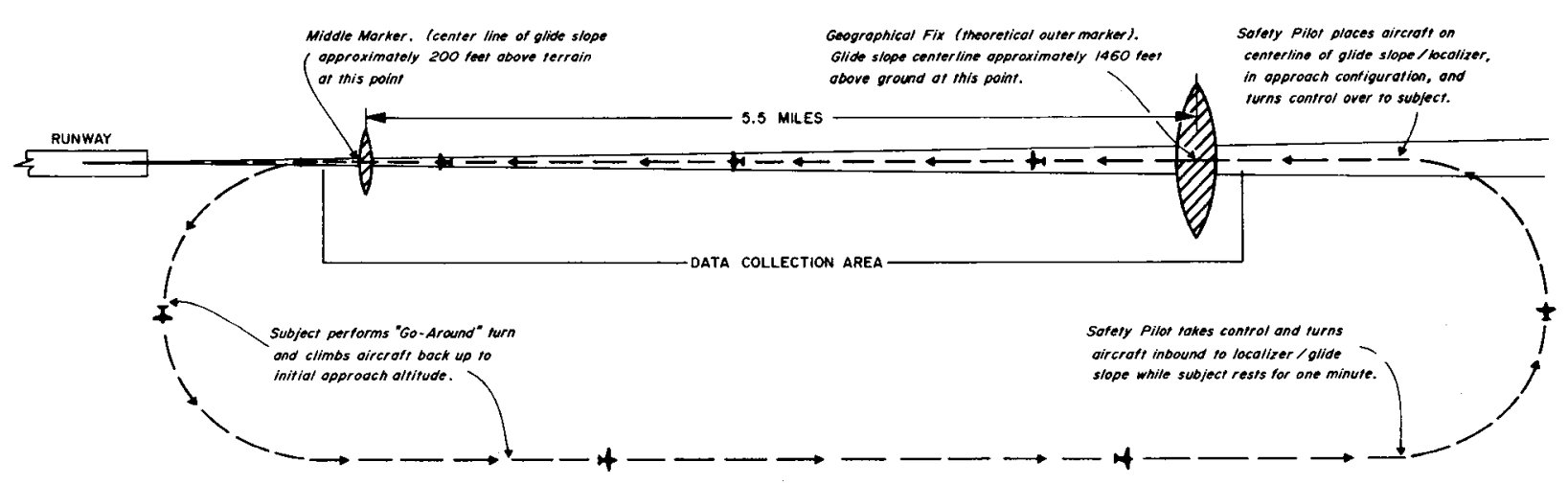

FIGURE 4. Flight path used for study of pilot performance during simulated instrument approaches.

After go-around, the subject climbed back to initial approach altitude; he was then given a 1-minute rest period while the safety pilot made a $180^{\circ}$ turn inbound to the glide slope/localizer centerline, where the procedure was repeated. The flight was terminated after the 10th approach, with the safety pilot landing the aircraft. 


\section{Results.}

The mean heart rates for the eight subjects during the 10 consecutive simulated instrument approaches are presented in Figure 5. The data points on each curve represent the mean heart rates derived from five 15 -second time periods spaced along the approach path to the middle marker as illustrated in Figure 6. The relative time intervals between the first and second time

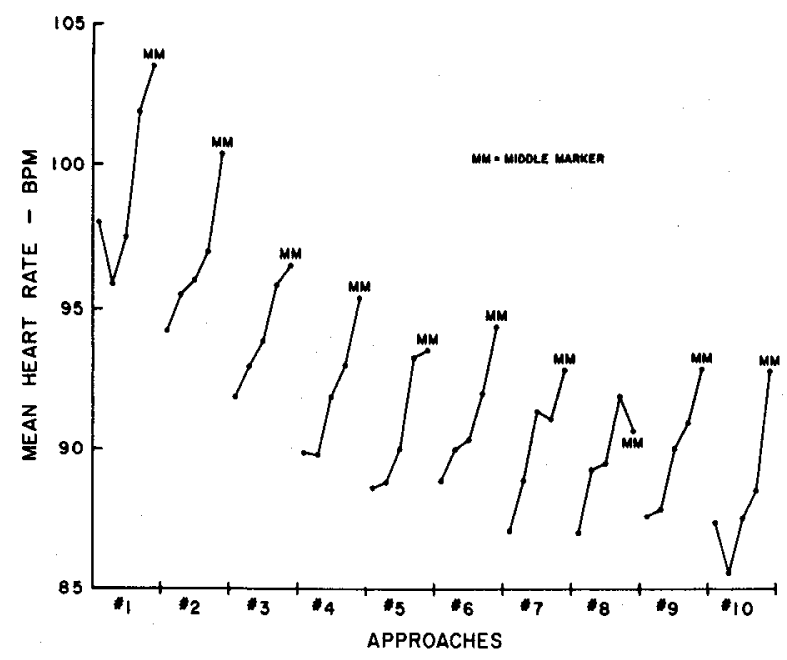

Figure 5. Heart rate means of eight pilots flying ten simulated instrument approaches. The points on each curve represent (from left to right) the mean rates for five 15-second time zones spaced along the approach p.ih to the middle marker. zones and between the fourth and fifth time zones (see Figure 6) have been shortened by a few seconds to facilitate data handling, but this minor accomodation is not considered to have a significant influence on the data or the validity of the analysis reported below.

Mean heart rate changes within approaches remained relatively constant throughout all approaches, ranging from 3.6 to 6.0 beats per minute (BPM). For eight of the 10 approaches, the increase was between 5.0 and $6.0 \mathrm{BPM}$. The mean increase for all 80 approaches was 5.2 BPM. Figure 7 illustrates the typical pattern of mean heart rate increase found in this study. Curve "A" traces the actual calculated data points for the combined data for all approaches while curve " $\mathrm{B}$ " is a straight line approximation that best fits the plotted data points. The values are plotted with reference to an in-flight mean "baseline" heart rate of 88.8 BPM established approximately 15 minutes prior to the first approach while the subject flew the aircraft in level attitude. The use of this mean reference value is merely a convenience and is not meant to imply a representative relationship between the base-. line value and the heart rate increases during any given trial, since the mean overall heart rates (to which the heart rate increases are referenced) decline on successive approaches.

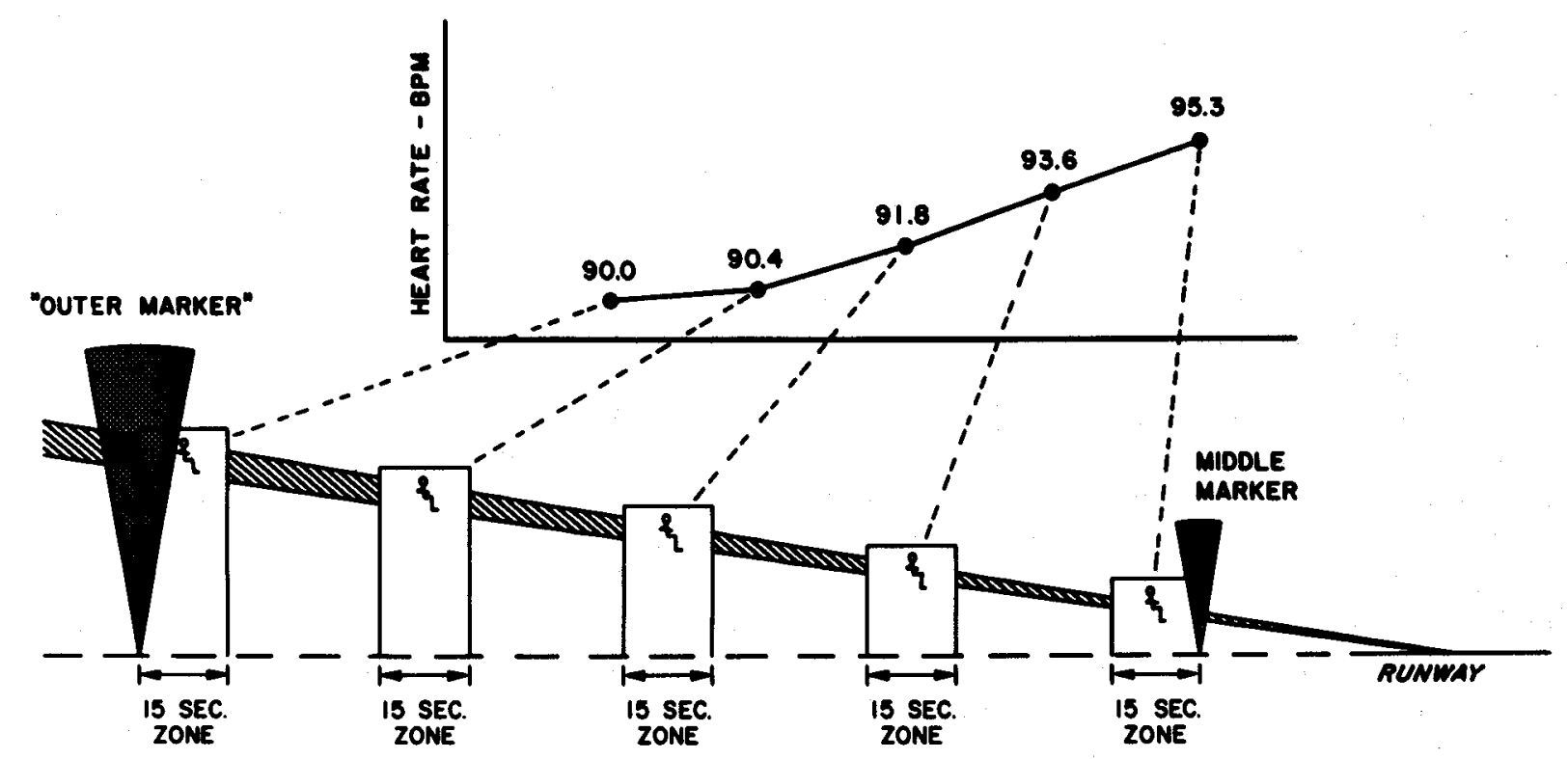

Figure 6. Heart rate data was collected continuously between outer and middle markers during approaches. Data used in this study was taken from five 15-second time zones spaced progressively to the middle marker. 
An analysis of variance was performed on the data and the results are presented in Table II. The increase in mean heart rate across time zones during the approaches was highly significant $(p=<.001)$. The absence of a significant interaction between heart rate changes during approaches and the number of approaches flown permits the combining of heart rate change data for all approaches. Though the combined data. as illustrated by curve "A" in Figure 7 , deviate somewhat from the straight line approximation of curve "B", the analysis indicates that only the linear component of the data is significant $(\mathrm{p}=<.001)$.

TABLE II.-Summary analysis of variance on heart rate data during successive instrument approaches

\begin{tabular}{|c|c|c|c|}
\hline Source & df & MS & $\mathbf{F}$ \\
\hline Approaches (A) & 9 & 479.48 & $7.79 *$ \\
\hline Linear & 1 & $3,656.12$ & $59.38^{*}$ \\
\hline Quadratic & 1 & 505.05 & $8.20 * *$ \\
\hline Other & 7 & 22.03 & $<1$ \\
\hline Time Zones (B) . ... & 4 & 386.61 & $20.28 *$ \\
\hline Linear & 1 & $1,485.13$ & $77.91 *$ \\
\hline Quadratic......... & 1 & 52.29 & 2.74 \\
\hline Other $\ldots$ & 2 & 4.52 & $<1$ \\
\hline Subjects $(\mathrm{C}) \ldots$ & 7 & & \\
\hline $\mathrm{A} \times \mathrm{B}$ & 36 & 6.67 & $<1$ \\
\hline$A \times C \ldots$ & 63 & 61.57 & $<1$ \\
\hline $\mathrm{B} \times \mathrm{C} \ldots$ & 28 & 19.06 & $<1$ \\
\hline$A \times B \times C$ & 252 & 7.43 & $<1$ \\
\hline Total_......... & 399 & & \\
\hline
\end{tabular}

$*_{\mathrm{p}}-.001$

$* * \mathrm{p}-.01$

The significance level for the mean heart rate changes during approaches was achieved in the presence of considerable variation in the direction and magnitude of individual changes, not only from subject to subject, but also from one approach to the next for the same subject. Fxamination of the data showed that some subjects, on some trials, had a lower heart rate at the middle marker than at the outer marker, and there were frequent instances of highest rates occurring at intermediate points.

The largest individual increase in heart rate between the outer and middle marker was $15 \mathrm{BPM}$ compared to the largest single decrease of 6 BPM. One subject with approximately 1,500 hours of flying experience had a maximum heart

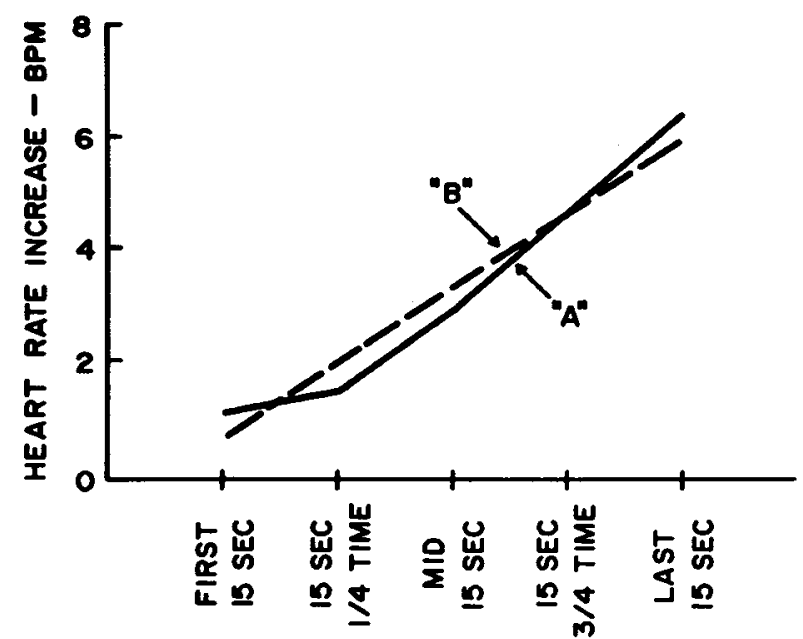

FIguRe 7. Heart rate changes during in-flight simulated instrument approaches as a function of time and distance along the approach.

rate variation of only $5 \mathrm{BPM}$, not only within a single approach but throughout all 10 approaches. During six of the approaches, his maximum variation was 2 BPM or less.

Because the maximum range of heart rate change frequently did not coincide with the heart rate values at the onter and middle markers, the difference between the highest and lowest rate for each subject within each approach was determined. The smallest maximum variation within any approach was $1 \mathrm{BPM}$ and the highest was 16 BPM. The means of maximum variations within individual approaches ranged from a high of 9.4 BPM to a low of $6.9 \mathrm{BPM}$. The mean of the maximum variations for all subjects on all approaches was 7.9 BPM, as compared to the mean increase of 5.2 BPM between the outer and middle marker. Except for the larger magnitude of the maximum variations, they did not appear to differ from the values based on the outer and midle marker with regard to their distribution across approaches. This conclusion was not tested statistically due to the apparent high correlation between the two measures.

Mean heart rate levels during each approach are presented in Figure 8. Curve " $B$ " is based on the average of the five data points of each approach as presented in Figure 5. The mean heart rate level declined a total of 11.0 BPM throughout the 10 approaches. As with heart rate changes during approaches, individual subjects varied considerably. Three subjects showed practically no change in mean heart rate between ap- 
proach \#1 and approach \#10. Two of the three showed a mean increase of 0.2 and 0.8 BPMI and the third a mean decrease of 2.0 BPII. The two largest individual decreases (24.0 and $26.2 \mathrm{BPM}$ ) coincide with the two subjects having the highest mean heart rates during approach \#1. No further attempt has been made to compare heart rate level, heart rate changes, in-flight baseline rates, flying experience, or age of subjects for the purposes of this part of the overall study. Curves " $\mathrm{A}$ " and "C" in Figure 8 are included for comparison only. They are the mean heart rate levels at the middle and outer marker respectively, and correspond to the last and first points of the curves in Figure 5. Curve "B" includes the values of Curves "A" and "C". All three curves have approximately the same shape except that the values for curve " $A$ " tend to be less consistent than the others.

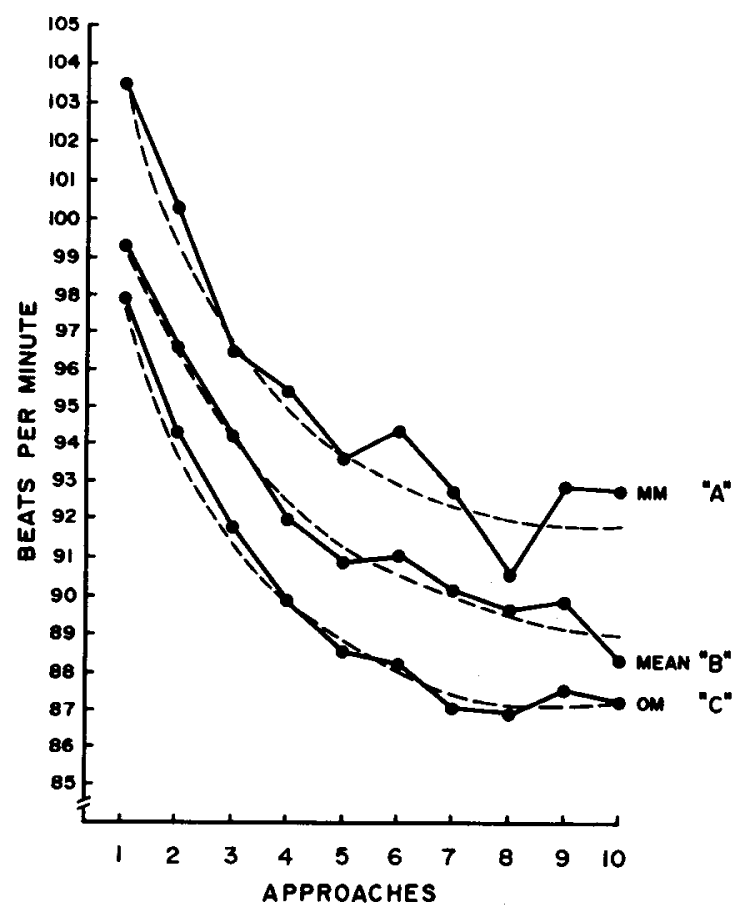

F'IGURE 8. Mean heart rate levels during each approach.

The analysis of variance reported in Table II shows the overall differences in heart rate levels between approaches to be significant $(p=<.001)$. Both the linear $(p=<.001)$ and the quadratic $(\mathrm{p}=<.01)$ components are significant. No attempt was made to partition the sequence of approaches to attribute a singular component to a particular segment of the function. Similarly, no subsequent tests of significance were performed on any pair combinations or to determine if the curve had reached an asymptotic value.

\section{Discussion.}

Two distinct and statistically significant heart rate patterns were exhibited by the subjects under the conditions of the experiment reported here. One was the long-term decrease in mean overall heart rate across successive approaches, and the other was the consistent increase in mean heart rates during each approach.

When endeavoring to equate changes in heart rate levels with changes in stress levels, it must be recognized that any apparent stress may be the result, not of a single type of stress, but rather of the complex interaction of a number of psychological and physiological factors operating concurrently. ${ }^{7}$ However, the main sources of stress assumed to be responsible for the heart rate changes found in this study can be roughly divided into two major categories: (a) The subjective elements introduced by the individuals and (b) those related to the objective difficulty of the task.

It seems reasonable to assume that the longterm decrease in overall mean heart rate can be equated to the classical accommodation (habituation) effect. This assumption is supported, in part, by the fact that the observed values are in excess of, but declining toward, the mean inflight baseline heart rate. This indicates that the elevated mean heart rates, especially those for the initial approaches, are indicative of a degree of stress to which the specific short-term task performance stressors are only a contributing factor. The source of this stress may be attributed largely to the highly subjective perceptions and expectations the individual brings to the total flying task. These may include, but are not limited to, his evaluation of fancied or real dangers in the situation ${ }^{1}$, his inherent and learned coping mechanisms for dealing with a particular type of stress ${ }^{6}$, his understanding of the instructions given him and the explanation of the purpose of the task ${ }^{3}$, his fear of failure-independent of the physical consequences of such failure ${ }^{5}$, and his sense of responsibility while having control of the aircraft. ${ }^{9}$

As successive approaches are completed, these sources of stress may be assumed to decrease in significance, though they probably are never com- 
pletely eliminated. This decrease in anxiety, and the resulting stress reduction, is brought about as the subject gains additional familiarity with the aircraft and the characteristics of the task, his real or fancied dangers fail to materialize as physical consequences, and he gains confidence in his ability to deal with an increasingly predictable environment. It should be noted that the reported heart rates, and rates of magnitude of change, are at all times well below those characterized by fright or fear as found during such stress-inducing activities as free-fall parachuting. ${ }^{10}$ The reported values may be more accurately compared to a mild anxiety or apprehension level when related to the in-flight baseline rate. Unfortunately, consideration dictated by limited data recording capacity precluded the gathering of data during the "go-around" portion of each circuit. Such data might have yielded some interesting insight on the heart rate changes resulting from the anticipation of initiating each subsequent approach. While the decrease in mean overall heart rate over the 10 approaches suggests a decline in apprehension as the subjects adapted to the total task, the lack of reduction in magnitude of the heart rate increase during each approach suggests an additional contributing factor. This factor is probably the stress resulting from the increase in task load as the middle marker is approached. To understand this increase requires an explanation of the pilot's task.

The difficulty of the task used in this study can be described in terms of the amounts and rates of information that must be obtained from the flight instruments, interpreted, and translated into psychomotor inputs to the aircraft's controls. In the present investigation, task performance was related primarily to maintaining the aircraft on the centerline of the localizer and glide slope while keeping the heading, rate of descent, and approach speed within specified limits.

Though all primary flight instruments play an important role in the performance of this task, the glide slope/localizer (cross-pointer) indicator is, by definition of the task, the primary "foreing" reference. That is, the aircraft position in space is referenced to the cues obtained from the cross-pointer indicator which, in effect, provides a forcing function on the pilot to fly his plane so as to meet the demands of the instrument.
Effective use of this instrument requires a basic understanding of its cueing characteristics. The horizontal (glide slope) needle moves vertically in reference to the bull's-eye (or "doughnut") and to a series of "dots" spaced in a vertical line above and below the center of the instrument. The span of the bull's-eye is equal to a subtended angle of approximately $0.28^{\circ}$ with reference to the vertex of the angle at the point of intended touchdown. The vertical distance between dots, and between the periphery of the bull's-eye and its center, is equal to a subtended angle of $0.14^{\circ}$. Since the distance between the top and bottom radii comprising this angle diminishes as the vertex is approached (Figure 9), it is obvious that the vertical distance equivalent to a "one-dot" dislacement is a function of the distance between the aircraft and the rertex of the angle. To find this distance, in feet, at any point along the approach path, the following equation may be used for approximation purposes:

$$
\begin{aligned}
\mathrm{S}= & \mathrm{S}_{\mathrm{h}}(.0025), \text { where } \\
\mathrm{S}= & \text { vertical distance in feet, and } \\
\mathrm{S}_{\mathrm{h}}= & \text { distance in feet between ground-based } \\
& \text { glide slope antenna and aircraft, and } \\
.0025= & \text { factor for one dot of glide slope needle } \\
& \text { displacement. }
\end{aligned}
$$

For example, the maximum vertical enrelope within which the aircraft must remain to keep the glide slope needle within the confines of the bull's-eye ( 2 dots) is about 100 feet at a point slightly less than 4 miles $(20,000$ feet) from the glide slope transmitter antenna, while at a point 2,000 feet from the antenna the same bull's-eye envelope comprises only 10 feet. From this, it can be seen that the task of keeping the glide slope needle within the center of the bull's-eye is equivalent to flying the aircraft from the base toward the apex of a narrow isosceles triangle. Thus, the human performance requirements inherent in this tracking task will vary in degree, depending upon (a) the location of the aircraft (b) the response characteristics of the total aircraft and instrument system; and (c) the velocity of the aircraft.

It follows that for a given rertical displacement of the aircraft at a given forward velocity, the distance and rate of movement of the glide slope needle across the face of the instrument will increase as the aircraft moves toward the middle marker. This means the pilot is faced not 

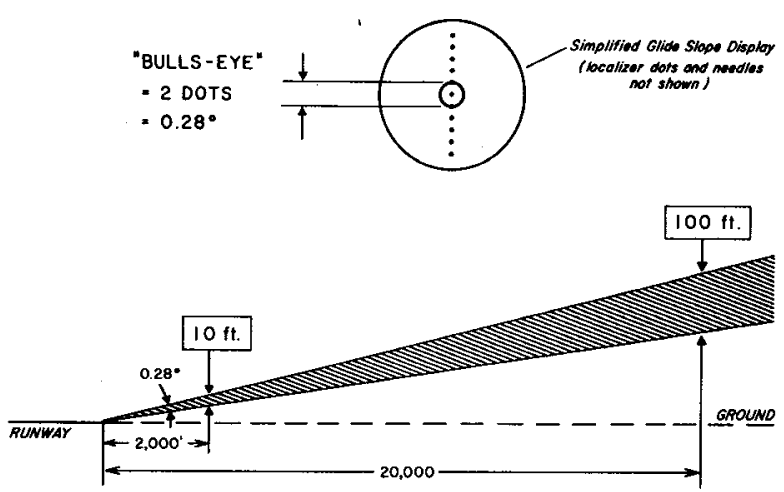

Figure 9. Two-dot deviation (equal to vertical displacement of glide slope needle across span of bull's-eye on center of indicator) is equal to about $0.28^{\circ}$ of subtended angle. This results in various "beam depths" depending on distance of aircraft from runway.

only with the necessity of increasing the speed of his cognitive, intellectual, and reactive processes, but he must also cope with a constantly changing control-display ratio that requires $d i$ minishing amplitudes of control input to achieve a given degree of corrective action as reflected on the cross-pointer instrument. These conditions impose a speed or pacing stress, at an increasing rate, which may sooner or later seriously impair the quality of his performance of the task.

In the present study, the effect of the pacing stress cannot be definitely separated from any stress which might be associated with anxiety related to the aircraft's decreasing altitude during the approach. There is some suggestion that flight near the ground - as at the middle markeras well as critical and demanding maneuvers, tend to add to the pacing stress. It should be pointed out that these increases have little, if any, clinical significance and may even be beneficial from an "alerting" point of view. Roman ${ }^{9}$ found that experienced military pilots flying high-performance aircraft exhibited higher heart rate levels than did their "passengers" (who were equally experienced pilots) during low-lerel "contact" (VFR) flights near the ground. These differences in stress levels were more pronounced for the more demanding or critical portions of the flights. 'This suggests that stress induced by performance demands may be more significant than the stress introduced by normally encountered risk-induced anxiety.

Overall mean heart rates and mean heart rate increases are, of course, influenced by a great many factors. The magnitudes of both measures reported in this study may be less than those that can be expected to be encountered in actual IFR/ILS approaches due to the modified workload in this study, and because of the security provided by the safety pilot who had visual contact with the outside world at all times. The variability of individual heart rate patterns during approaches may be attributed to the subjects' own perceptions of the quality of their performance at any given moment and may, or may not, coincide with the objective measures. Individual short-term reactions to incidental events in the environment, such as unexpected turbulence or increased activity of the safety pilot attempting to maintain visual contact with other traffic, may also significantly influence the results for a given subject on a given approach. Finally, the element or characteristic of the approaches that almost consistently coincided with the highest mean heart rate increase was the onset of over-control of the aircraft by the pilot, as indicated by rapid and extensive oscillations of the glide slope needle. This over-control may be attributable to the pilot's lack of ability to adapt adequately to the changing control-display relationship.

\section{Summary and Conclusions.}

Heart rate data were recorded on eight commercial or ATR instrument rated pilots during a total of 80 simulated in-flight instrument approaches. Analysis of the data indicated that:

1. Mean heart rate changes were relatively constant throughout all approaches.

2. Mean heart rate increases ranged from 3.6 to 6.0 BPM for the 10 approaches of each flight, with a mean increase of $5.2 \mathrm{BPM}$ for all 80 approaches.

3. Individual heart rate changes between the outer and middle markers ranged from a decrease of $6 \mathrm{BPM}$ to an increase of 15 BPM.

4. Individual maximum variations within approaches ranged from $1 \mathrm{BPM}$ to $16 \mathrm{BPMI}$ and averaged $7.9 \mathrm{BPM}$ for all 80 approaches.

5. Overall mean heart rate declined 11.0 BPM across the 10 approaches.

6. All heart rate levels were well below those generally associated with activities nor- 
mally considered to be highly stress inducing, such as free-fall parachuting.

7. Heart rate changes during approaches appear to be related to the pacing stress induced by specific characteristics of the man-machine interface.

Even a cursory survey of the human factors research literature indicates that relatively little is known about the effect of stress on total pilot performance. Though there are many potential sources of stress that may be operating at any given time during a flying mission, the stress resulting from inadequately designed man-ma- chine system interfaces is probably the most pervasive, consistent, predictable, and amenable to modification. Fox et al. ${ }^{2}$, have presented a very succinct statement of the type and extent of research effort required to gain the information necessary for an understanding of the airplanepilot system. As part of such a research program, it is suggested that a major effort be directed toward identifying and evaluating the sources of human stress in the airplane-pilot system interface under the widest possible range of flight conditions. On the basis of information gathered in this area, it should be possible to design safer and more efficient systems.

\section{REFERENCES}

1. Bjurstedt, H. and Mattell, G., "Cardiovascular and Respiratory Reactions in Mental Stress." In I. Levi (Ed.) Emotional Stress. Proceedings of an International Symposium. Forsvarsmedicin, Vol. 3, Suppl. 2, Stockholm, 1967.

2. Fox, J. G., Ferguson I., and Andrew, I. D. C., "An Annotated Bibliography of Presentation of Information in Aircraft Cockpits." $\mathrm{S} \& \mathrm{~T}$ Memo $3 / 66$, p. 77-78. Technical Information and Library Services, Ministry of Aviation, May 1966. (Available as AD 634575 ).

3. Frankenhanser, M., "Some Aspects of Research in Physiological Psychology." In L. Levi (Ed.) Emotional Stress. Proceedings of an International Symposium. Forsvarsmedicin, Vol. 3, Suppl. 2, Stockholm, 1967.

4. Harris, W., Mackie, P. R., and Wilson, C. L. Research on the Development of Performance Criteria, Technical Report VI: "Performance Under Stress." Washington, Department of Navy, July 1956.

5. Lager, C. G., "Experimental Methods and Results of 'Stress' Measurements in Simulated Flight." In
L. Levi (Ed.) Emotional Stress. Proceedings of an International Symposium. Forsvarmedicin, Vol. 3, Suppl. 2, Stockholm, 1967.

6. Lazarus, R. S., "Stress Theory and Psychophysiological Research." In L. Levi (Ed.) Emotional Stress. Proceedings of an International Symposium. Forsvarsmedicin, Vol. 3, Suppl. 2, Stockholm, 1967.

7. Levi, I., "Some Principles and Sources of Error in Psychophysiological Research." In L. Levi (Ed.) Emotional Stress. Proceedings of an International Symposium. Forsvarsmedicin, Vol. 3, Suppl. 2, Stockholm, 1967.

8. Melton, C. E., Wicks, M., Saldivar Jr., J. T., Morgan, J., and Vance, F. P., "Physiological Studies on Air" Tanker Pilots Flying Forest Fire Retardant Missions." OAM Report AM 68-26, 1968.

9. Roman, J., "Risk and Responsibility as Factors Affecting Heart Rate in Pilots." The Flight Research Program-II. Aerospace Med. 36: 518-523, 1965.

10. Schane, W. P. and Slinde, K. E., "Continuous EKG Recording During Free-Fall Parachuting." USAARU Report No. 67-7, 1967. 